This is a self-archived version of an original article. This version may differ from the original in pagination and typographic details.

Author(s): Jakonen, Teppo

Title: Retrospective Orientation to Learning Activities and Achievements as a Resource in Classroom Interaction

Year: 2018

Version: Accepted version (Final draft)

Copyright: (c) National Federation of Modern Language Teachers Associations

Rights: In Copyright

Rights url: http://rightsstatements.org/page//nC/1.0/?language=en

Please cite the original version:

Jakonen, T. (2018). Retrospective Orientation to Learning Activities and Achievements as a Resource in Classroom Interaction. Modern Language Journal, 102(4), 758-774.

https://doi.org/10.1111/modl.12513 


\title{
RETROSPECTIVE ORIENTATION TO LEARNING ACTIVITIES AND ACHIEVEMENTS AS A RESOURCE IN CLASSROOM INTERACTION
}

\author{
Teppo Jakonen \\ Department of Language and Communication Studies \\ University of Jyväskylä, Finland
}

Manuscript after peer-review, accepted for publication in The Modern Language Journal. 


\section{Retrospective Orientation to Learning Activities and Achievements as a Resource in Classroom}

Interaction

\section{$<$ A $>$ ABSTRACT}

This article explores the temporal nature of language learning in classroom settings through the lens of Conversation Analysis by drawing on video-recorded interactions from Content and Language Integrated (CLIL) classrooms. It outlines some methodological challenges that the task of documenting language learning in and as observable social interaction poses for CA studies of L2 learning, and proposes that learning has typically been described as either a situated activity (in cross-sectional studies) or intermediate achievement (in longitudinal studies). The empirical analysis focuses on interactional instances in which students observably invoke and describe their earlier learning activities or achievements as part of some on-going classroom activity, either in whole-class or peer interaction. It is argued that such instances of a retrospective orientation to learning offer empirical materials for examining learning trajectories from a participant's perspective, how connections between moments and social domains separated by time and space are forged, and how this work allows resources to be accumulated, recalibrated, and put to use. The focal interactions also raise conceptual implications for the ways in which learning is both situated and transferable, as well as methodological implications for how retrospection can best be rendered analytically accessible by way of a CA approach. <END OF ABSTRACT>

Keywords: CA-SLA; classroom interaction; learning-in-interaction; content and language integrated learning (CLIL) 
While SLA is home to a range of research paradigms that each have a distinct ontological, methodological, and epistemological approach to what constitutes language learning, there appears to be some consensus that learning however defined is inherently temporal, in other words, it involves some kind of change over time (see e.g., Ellis, 2010; Larsen-Freeman, 2007; Ortega \& Iberri-Shea, 2005). Therefore, researchers drawing on either a cognitivist or a social framework (see Ortega, 2011) face the task of demonstrating change over time as evidence for learning. Within Conversation Analytic literature on L2 learning (CA-SLA), this task has perhaps most systematically been pursued in studies investigating learners' developing ${ }^{1}$ interactional competence (e.g., Pekarek Doehler \& Berger, 2016) and CA studies in the usage-based framework of language learning (e.g., Eskildsen \& Wagner, 2015). In these contexts, a discussion has also emerged on how-and in what kinds of timescales-language learning manifests itself in social interaction (e.g., Pekarek Doehler \& Berger, 2016; Pekarek Doehler \& Lauzon, 2015).

The purpose of this article is twofold. First, the article reviews existing CA-SLA literature and argues that cross-sectional and longitudinal studies of learning in interaction afford different perspectives to learning, which are to some extent an analytical consequence of the selected study design. Briefly put, whereas the analysis of single interactions of 'doing learning' allows language learning to be described as a situated activity to which participants observably orient, a longitudinal approach to tracking comparable objects across time is well fitted to demonstrating the emergence of learning as (intermediate) achievements, but it involves the risk of losing sight of participants' own orientations. Second, the article illustrates an alternative entry point into analysing the temporal nature of learning, that of examining single interactions where participants observably invoke or describe a prior learning experience in the here-and-now of some current activity. An analysis of these kinds of interactions shows that participants make connections between moments across time, which suggests that they have ways to observably construct change, revisit instances of prior learning, and connect 
different domains of their lifeworlds. The implications of these findings are discussed in terms of situated vs. transferable conceptualisations of learning and the methodological challenges that the demonstration of learning by way of the CA approach involves.

\section{<A> LANGUAGE LEARNING AS A TEMPORAL AND OBSERVABLE MEMBERS' PHENOMENON}

Most researchers within SLA would likely agree that language learning is a complex, multifaceted, and above all, temporal phenomenon. For example, Larsen-Freeman (2007) notes that "[a]ny definition of learning must involve the transcendence of a particular time and space” (p. 783). Seen this way, 'time' becomes a key matter to address also for the growing body of research that uses Conversation Analysis to investigate how L2 learning takes place in and through social interaction (CA-SLA). CA, which has its origins in Harold Garfinkel's ethnomethodology, offers a microanalytical perspective to investigate L2 learning as accountable-or, to use Garfinkel's (1967) phrasing “observable-and-reportable” (p. 1)social action. A defining feature of CA is its methodological strive to take the emic perspective (participants' own observable orientations) as the starting point of an analysis of interaction. Thus, as Sacks, Schegloff, and Jefferson (1974) forcefully maintain, “[s]ince it is the parties' understandings of prior turns' talk that is relevant to their construction of next turns, it is their [original emphasis] understandings that are wanted for analysis" (p. 729).

In very broad terms, prior CA-SLA inquiries have approached learning either through crosssectional analyses that examine how learners' situated interactional work may occasion changes in understanding or knowing, visible within single interactional episodes, or more recently, with longitudinal studies documenting changes in a learner's language practices over longer periods of time (for a recent overview, see Eskildsen \& Majlesi, 2018). Quite apparently, each of these two approaches 
investigates change from a temporally different perspective and, as is argued here, paints a slightly different image of what learning is.

Cross-sectional studies typically address L2 learning by investigating interactions in which participants observably orient to the on-going activity as learning (as opposed to some other social activity) by identifying and working on 'learnables' (Majlesi \& Broth, 2012). These kinds of situated learning practices have been explored both in pedagogical settings (e.g., Lee, 2010; Majlesi \& Broth, 2012; Merke, 2016; van Compernolle, 2010) and in everyday life (Eskildsen, 2018; Lilja, 2014; Sahlström, 2011; Theodórsdóttir, 2018). Recent work within this literature has examined points of convergence and divergence between the classroom and 'the wild', with a view on how these life arenas may involve distinct interactional practices for doing learning, and how participants may build bridges between settings (see e.g., Eskildsen \& Theodórsdóttir, 2017; Lilja \& Piirainen-Marsh, 2018). Yet another focus in the cross-sectional inquiry is represented in the body of literature that takes as its starting point well-established cognitive constructs of SLA to explore their social organisation and interactional building blocks. These studies have re-specified notions such as planning (Lee \& Burch, 2017; Markee \& Kunitz, 2013), noticing (Kääntä, 2014; Kunitz, 2018), corrective feedback (Theodórsdóttir, 2018), and communication strategies (Burch, 2014) as interactionally observable phenomena of situated cognition (see Kasper, 2009) and thereby within the reach of a CA methodology.

For the analyst, a key challenge in identifying a participant orientation to learning in some single interaction is how to tell when this happens without some kind of an a priori definition of learning, in line with CA's methodological insistence on the emic perspective. One strategy would be to look for instances where participants actually refer to conduct by using the word 'learning.' Other possibilities would be to approach the data with an extrinsic learning theory (for a related methodological discussion, see Hauser, 2011) or employ a rough working definition of what kinds of temporal 
transformations might be learning-relevant. Some helpful albeit relatively loose definitions are emerging in the CA-SLA literature. For example, Eskildsen and Theodórsdóttir (2017) note that participants treat "the goings-on as learning" when they observably orient to "understanding/using something new/recently learned" (p. 144). Moreover, such attempts at doing what one has not done before can be "revealed by linguistic and non-linguistic behaviours" (Gardner, 2008, p. 238). However, it should also be acknowledged that, while prior CA-SLA studies have shown learning activities taking place in situations where understanding problems become visible and addressed through conversational repair (e.g., Hellermann, 2009; Lilja, 2014), the maintenance of understanding is neither conceptually nor empirically the same as learning. Indeed, as Kasper and Wagner (2018) observe, the work of identifying and acting on learning objects involves an activity shift from "achieving intersubjectivity to doing learning” (p. 83). Moreover, learning can also be an activity that participants do for its own sake, such as when small children entertain themselves by learning to count in the L2 (Sahlström, 2011).

Existing longitudinal CA-SLA studies have tracked temporal changes in interaction to explore L2 speakers' learning of linguistic form and vocabulary (Eskildsen \& Wagner, 2015; Hauser, 2013, 2017; Markee, 2008) and their developing ways of accomplishing social actions or courses of action in investigations of L2 interactional competence (Cekaite, 2007; Hellermann, 2011; Hellermann \& Cole, 2009; Nguyen, 2011; Pekarek Doehler \& Berger, 2016). Not only have longitudinal studies thus addressed a diversity of learning objects, but there is also a difference in the timescales of the documented learning trajectories, ranging from just a few days (e.g., Markee, 2008) to years (e.g., Eskildsen \& Wagner, 2015). For example, Hauser (2017) showed how the word 'near' was first met and repaired, and subsequently used a number of times by an L1 Japanese learner of English over a 7month period in a conversation-for-learning setting. Eskildsen and Wagner (2015) demonstrated how an L1 Mexican Spanish learner of English began using the prepositions 'under' and 'across' with the help of specific gestures, documenting how those gestures were also part of later usages of the two 
words. Pekarek Doehler and Berger (2016) described how an L1 German-speaking au-pair's storyopenings changed over nine months in a French-speaking host family. In contrast to cross-sectional work, these and other longitudinal studies document how long-term changes beyond the single moments of 'doing learning' take place gradually, both via the accumulation of language resources and the diversification of 'methods' for social action.

Cross-sectional and longitudinal studies offer complementary approaches to how L2 learning proceeds through social interaction, yet there appears to be a certain analytical trade-off between them in relation to the emic perspective and what part of 'learning' they can render observable. While longitudinal studies can show trajectories of change beyond the single interactions of a cross-sectional analysis, possibly across interactional contexts, the tracked instances of using a particular language object do not necessarily involve a participant's orientation to learning. Thus, even if the documented longitudinal learning trajectory may begin from a situation where, for example, understanding is problematic and a new linguistic item or a social action is overtly practiced, at some point along the sketched trajectory the same item or action typically loses its status as a learning object to the participant. This is the case, for example, in Eskildsen and Wagner's (2015) and Hauser's (2017) studies that showed how the learner initially problematized a word ('under' and 'near', respectively) and started using them with increasing fluency and dexterity. Yet, in most of the documented subsequent instances of using the word, no such observable orientation to 'doing learning' or the public construction of a learning-relevant transformation having to do with learning were apparent.

The two different perspectives to change can be seen in terms of a distinction between learning as action or achievement (or 'process' and 'product'). Perhaps somewhat paradoxically, longitudinal studies are not primarily designed to illustrate the process of learning if that is seen as the situated and contingent work of identifying and acting on learning objects, work where learning is the oriented-to interactional business. Instead, they capture intermediate products of development, or as Pekarek 
Doehler (2010) puts it, "a state of competence at a time X, X +1" (p. 121). This means that the situated work of learning activities can take place between the documented states of competence, between recorded interactions collected at intervals and subjected to longitudinal analysis (such as weekly classes or conversation-for-learning meetings).

Within the CA literature that addresses learning other than 'language', there is debate as to whether or not learning is observable at all in the details of social interaction (and thereby within the reach of a CA methodology), and if it is, whether it should be seen as an achievement or action (see, e.g., Gardner, 2008; Macbeth, 2014; in language learning contexts, Seedhouse, 2010, p. 251). Macbeth (2014) has criticised educational research for a conceptual confusion that the unexamined everyday usage of the word 'learning' as a verb describing action, not achievement, creates. In Macbeth's words, "the pursuit of learning as a hidden process has been paradigmatic for modern educational research" (p. 301), even if, in his view, learning is fundamentally an achievement and thereby not describable as an action. On the other hand, it is hard to see how achieving learning would not be intimately connected to (inter)action that precedes and enables it, such as a learner's pursuit to learn or a teacher's instructing action. In any case, Macbeth's critique draws attention to the relationship between the conceptualisation of learning and the time(s) and place(s) in which learning becomes observable-if it does. As it stands, the problem of documenting learning in the details of social interaction remains a controversial issue within the CA community. Some researchers such as Gardner (2008) appear more cautious in stating that "moments of learning may be unlocatable" (p. 236), whereas others such as Koschmann (2013) maintain that the problem is one of (mis)conceptualising learning as an "unobservable, occult matter" instead of "a public and accountable process" (p. 1041). ${ }^{2}$

The main reason for this undoubtedly selective review of CA-SLA literature is not to suggest that either cross-sectional or longitudinal approach to studying language learning in social interaction would be inherently more suitable to the task than the other. Quite the opposite, they can be seen as 
complementing each other: As Seedhouse (2010) notes in connection to discussing process and product orientations "there are many advantages to employing both orientations in the same research study" (p. 251). If anything, the purpose is to highlight the multidimensional and elusive nature of the central research object in CA-SLA. As such, the elusiveness presents a practical problem not only for CASLA scholars but also for other research frameworks in SLA and beyond in educational sciences. At the heart of such elusiveness is time and the temporal nature of learning and, more generally, of human experience. Thus, if we reconsider Gardner's (2008, p. 236) assertion about the unlocatability of learning moments from a temporal perspective, perhaps the problem is that locating learning in one place and time in effect strips the phenomenon of its temporality and dynamism. In other words, if learning is change or a transformation, then it is fundamentally a relation between at least two points in time, two 'doings,' 'knowings,' or 'understandings,' which means that it is by definition unlocatable in one single moment but involves connections between moments. The question then becomes how exactly these connections are made.

These kinds of "lived temporalities" (see Deppermann \& Günthner, 2015, p. 3) of language learning are under scrutiny in the remainder of this article. The empirical analysis investigates how learners retrospectively refer to prior learning experiences, either a prior learning achievement or activity, in whole-class or peer interaction in Content and Language Integrated (CLIL) classrooms. As such, the study aims at building bridges between cross-sectional and longitudinal approaches in that it considers ways to approach what are essentially single interactional sequences from a temporal perspective. While this might seem like a paradoxical strategy for researching learning, its potential payoff is that it can offer an entry point to examining language learning as a time-bound activity "while preserving [CA's] programmatic attention to the contingent interpretive actions of the parties in each interaction" (Lee \& Hellermann, 2014, p. 766). Thus, a focus on retrospective orientation to prior 
learning can shed light on how learners themselves 'do learning' by constructing change over time as opposed to being individuals to whom change happens.

\section{$<$ A $>$ DATA AND METHOD}

This study uses classroom interaction data from a corpus of 22 CLIL lessons, video-recorded as part of different research projects in Finland between 2003 and 2011. CLIL is a bilingual educational approach where academic subject contents are taught through a foreign language (for overviews, including differences to other bilingual programmes, see Dalton-Puffer \& Smit, 2013; Nikula \& MårdMiettinen, 2014). For this article, I draw on interactions in two content subjects: Physics (grade 7) and British history (grade 8), which were taught at two different lower secondary schools. Both schools had what could be characterised as a small-scale CLIL programme, which relied heavily on individual teachers' willingness and readiness to teach their subjects through English. The teachers and the students in the programme had Finnish as their L1.

The data extracts analysed in this article show interactions that took place during different kinds of whole-class activities, either between a student and the teacher or between students. They are part of a small collection in which a student's prior learning is made relevant for the on-going talk. By this I mean situations in which participants invoke a prior transformation related to knowledge, understanding, or a skill in a way that they also 'localise' it to a specific context, either by implication or by explicitly describing the time and place of prior learning. The collection also includes interactions where participants retrospectively describe situations where achieving learning has been problematic in that no such transformation has occurred. To give examples, retrospection is evident when a student claims to have learned a particular word by playing a video game (see also Jakonen, 2014) or explains how she tackled a homework task that she "didn't get." Participants can also attribute prior learning 
achievements (or problems) to others, for example when the teacher 'signposts' instruction by saying what the class is supposed to "remember" from the previous lesson (see Andrée et al, 2017; Melander \& Aarsand, 2017, for these kinds of interactions in content classrooms) or asks the students to report task items that they have found difficult during some prior task activity.

The focal phenomenon bears some resemblance to interactions described in Koole's (2010) study that showed how teachers routinely invite two kinds of epistemic displays from students while explaining mathematics to them: displays of having known or having acquired access here-and-now. The first kind of display is visible when teachers ask questions of the type "Do you know what X is?" and students respond with a turn formatted along the lines of "Yes, it's Y", thereby claiming and demonstrating 'already knowing'. Even though the participants thus orient to prior knowledge in sequences such as these, the student turns described by Koole (2010) are distinctly a-temporal in that they do not invoke when or how the student would have come by such knowledge. This differentiates them from the often quite elaborate descriptions of prior learning activities, circumstances, or mental states in the present data collection. Another relevant study is that by Lilja and Piirainen-Marsh (2018), who analysed interactions during a pedagogical activity whereby adult L2 Finnish learners participated in real-life service encounters, video-recorded their interactions, and later shared their experiences in the classroom. As part of the classroom task, the learners re-enacted and reported speech from the service encounter and worked to develop their understanding of a problematic aspect in it (a clerk's use of a particular response particle) while sharing the video with their peers. Thus, those interactions share with this study the observable retrospective orientation, but they differ in that the interactions investigated in this study occur within activities that have not been designed to foster retrospection in the first place.

The beginnings of the collection are in an observation that sometimes reports of personal learning experiences appeared to be weaved into routine classroom work. As it stands, the collection contains 24 
interactions that have been gradually accumulated, not as a result of a systematic 'trawling' of the whole corpus. In these instances of interaction, the retrospective references deal with a broad spectrum of learning objects, ranging from word meanings through cultural/lexical differences between American and British English to more 'content-related' objects relevant in the CLIL classroom such as how to explain a physics calculation task. Thus, the learning achievements and activities that participants report in these interactions can deal with (lexical) knowledge, understanding or skills. It is possible that the diversity of these objects reflects how, in the kind of pedagogical context that CLIL is, language and language learning become relevant for students in ways that are inextricably related to focal subject contents (on the concept of language and content integration, see Nikula et al., 2016). ${ }^{3}$

This article is an attempt to investigate through the lens of CA what participants might be accomplishing with these references to prior learning. Participants' talk has been transcribed with standard CA conventions (see Appendix), and, while the primary focus of this article is not on multimodality of interaction, transcripts integrate screenshots illustrative of the participation framework in the situation. Turns that contain Finnish have been translated into English. To protect students' identities, all names are pseudonyms.

\section{<A>REFERRING TO PRIOR INSTANCES OF LEARNING IN THE CLASSROOM}

This section illustrates how a retrospective orientation is used in two different participation frameworks during whole-class interaction, in talk between a teacher and a student and between peers. First, the analysis describes how a shared event of 'teaching' an L2 word in peer interaction (Excerpt 1) and an even earlier private life experience can be retrospectively invoked a week later in the next class in order to recalibrate the meaning of the taught word (Excerpt 2). After that, the use of retrospection as an interactional resource is analysed in two instances of teacher-student interaction, in both of which a 
demonstration of a learning achievement is expected from a student. In Excerpt 3, the teacher invites students to recognise an L2 nursery rhyme, and as a student conveys a context where the class has learned it, she is invited to recite the rhyme for the class, a task that takes peer support to accomplish. In Excerpt 4, a student is trying to demonstrate a learning achievement to the teacher in the form of telling in L2 how to do a physics homework, but as problems arise, she reports her (unsuccessful) taskresolving process in detail as a way to account for the absence of the achievement.

\section{$<B>$ References to Prior Learning in Peer Interaction}

Excerpt 1 takes place as the teacher is instructing a task (filling a task sheet) and has just made a

joke about its boring nature, promising that next week the students will get to bake a Yorkshire pudding as their homework, as a "consolation.” This brief announcement occasions Sylvi to initiate repair in L1 on the meaning of pudding, which she other-selects (Bolden, 2011) her peers Alma, Tuuli, and Esteri to produce at line 1 .

<INSERT EXCERPT 1 ABOUT HERE>

EXCERPT 1. Peer-Teaching a Word Meaning (Yorkshire pudding)

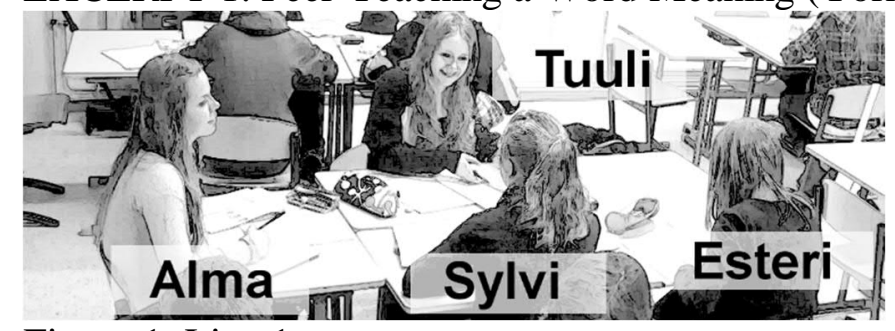

Figure 1. Line 1.

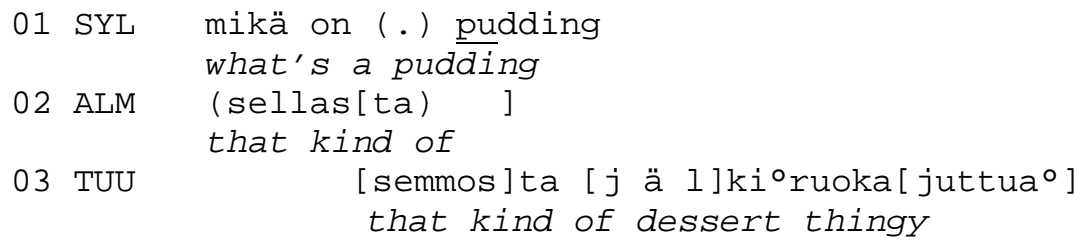




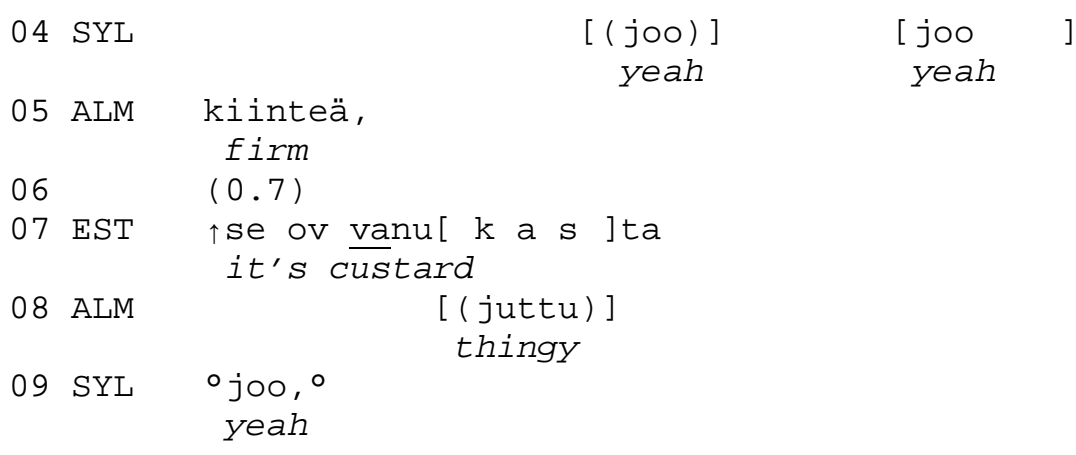

Note that the repair initiation targets only the latter part of the compound noun that the teacher has mentioned. At lines 2-3, both Alma and Tuuli begin to explain the word by identifying a broader category of foods to which pudding belongs ('dessert thingy') and describing its texture ('firm'). Sylvi acknowledges these contributions at line 4. After a silence, Esteri provides a Finnish-language translation of the item at line 7, in overlap with what seems like Alma's continuation of line 5. Different from line 4, Sylvi's acknowledgement token at line 9 is softly spoken and has a continuing intonation, features which may potentially index a less than enthusiastic receipt of such a third contribution. In brief, Sylvi's question is treated as a public indication of a lexical knowledge gap, visible in how her peers orient to teaching the item by explaining, describing and translating it in a manner that takes a distinctly knowledgeable stance (see Heritage, 2012).

Excerpt 2 shows how the students continue coming to terms with the meaning of (Yorkshire) pudding one week after. The students are now being instructed for their homework, having just seen a video showing how to bake Yorkshire pudding that in essence shows them that it is far from 'custard'. In what follows, Esteri, Alma, and Sylvi invoke the shared discussion of Excerpt 1 to account for the apparent discrepancy by way of referring to their earlier knowledge displays as 'beliefs' and 'thoughts. ${ }^{4}$ 
EXCERPT 2. Recalibrating Earlier Lexical Knowledge (Yorkshire pudding)

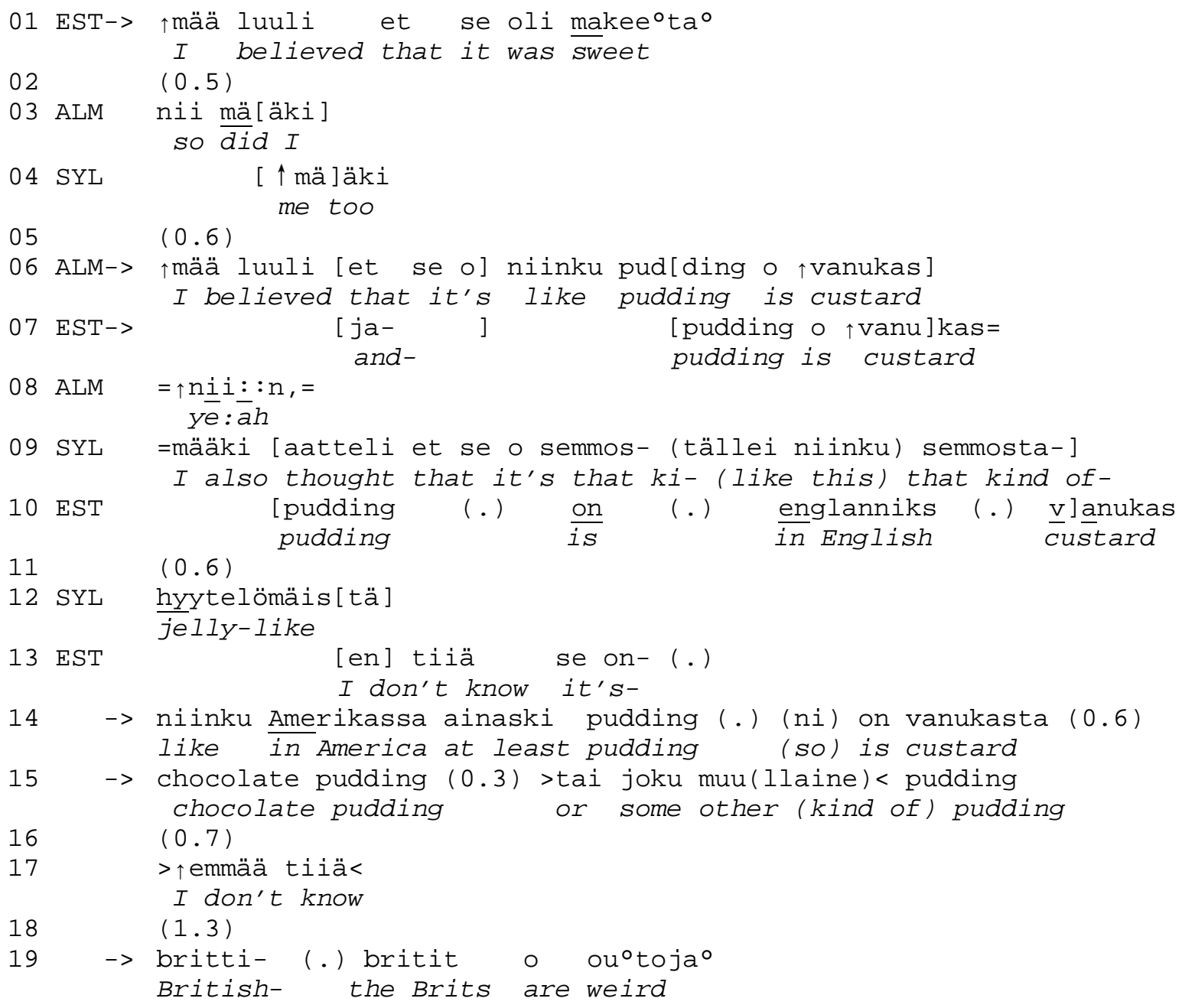

By way of its timing shortly after the class has finished watching the baking video, Esteri's telling at line 1 is hearable so that 'it' refers to Yorkshire pudding. Delivered with a rising turn-initial intonation, the turn has a character of wondering, and it achieves two things: First, it implies that Yorkshire puddings are in fact not sweet, as indeed shown on the video. Secondly, it conveys a prior weak epistemic stance by claiming that the speaker had at some (non-specified) point in time 'believed' that they would be 'sweet,' which is now proven erroneous, much to the surprise of the speaker.

The announcement receives overlapping agreement tokens from Sylvi and Alma (3-4). These responses not only claim an equivalent earlier belief as regards what Yorkshire puddings are but do so 
in a way that matches the emphatic design of Esteri's turn, conveying surprise by way of turn-initial pitch rise and word stress. After a short silence, Alma goes beyond merely agreeing and claims that her earlier belief was more specific and thereby an independently held one (see Heritage \& Raymond, 2005): that Yorkshire puddings are not only 'sweet,' but also, and more precisely, 'custard' (vanukas). The claim is collaboratively accomplished, as Esteri overlaps to complete the turn (7). Alma confirms Esteri's informing with a Finnish response particle nii ('yeah'), which is routinely used to claim affiliation and equal epistemic access (Sorjonen, 2001, pp. 280-281). Thus, the animated, quick, and overlapping manner in which these 'beliefs' are reported is a way to co-construct them as shared as opposed to merely receiving or acknowledging Esteri's personal thought.

At line 10, Esteri insist with a staccato assertion that in English pudding means 'custard,' stressing each word-initial syllable. Partly overlapping with the assertion, Sylvi (whom the word pudding was taught in Excerpt 1) produces a display of a previous 'thought' that Yorkshire pudding is 'jelly-like' $(9,12)$. Esteri's subsequent turn (13) contains a turn-initial claim of no knowledge, which suggests that she could be in search of a plausible explanation to the incongruity of word meaning by conveying less than full committal to her turn-to-follow (see Weatherall, 2011). However, Esteri quickly cuts off and moves to account for the apparent discrepancy between prior knowledge and perception by maintaining that 'custard' is what the sense of the word is 'in America' and giving an example of its usage (chocolate pudding, 14-15). This account makes visible another subtle retrospective reference, one that operates on a broader timescale, as Esteri claims knowledgeability by way of invoking her earlier experience of living in the United States, which constitutes background information that other classroom members (and researchers who followed these lessons) were well aware of. Following a silence (16), Esteri pushes the topic of regional variation in English use even further than the 'at least' account (14) as she dismisses other kinds of word meanings as the 'Brits' being 'weird' (19), thereby making word use a matter of moral normativity. The invocation of Esteri's 
personal stay-abroad experience has the effect of terminating others' talk in this situation, transforming the activity from one of sharing thoughts into Esteri's personal story, which suggests that it has considerable epistemic strength in the local setting.

Taken together, Excerpts 1-2 illustrate a retrospective orientation to two different kinds of prior experiences, an occasioned learning activity in peer interaction involving teaching a lexical item to one group member; and one student's linguistic expertise and cultural knowledge that she has amassed while living in a target-language country. In Excerpt 2, retrospection allows these experiences to be mobilized to manage what counts as knowledge, beliefs, and thoughts in the light of a new surprising experience (the baking video). It offers a way for these students to not only construct change by relegating what they earlier knew as a 'belief,' but also to resist such change by holding on to accumulated expertise (Esteri).$^{5}$

\section{$<B>$ References to Prior Learning in Teacher-Student Interaction}

Retrospective references to prior learning also feature in teacher-student interaction, for example, when teachers convey what students should know by saying things like "you remember from yesterday that when we increase force, the elastic material will be expanded more" (in Physics) or when they invite someone to summarise what was covered in the previous class. Turns like these invoke a prior learning experience and an achievement that is expected to have been taken away from the experience in order to contextualise current instruction and link it with already covered topics. Besides this kind of 'signposting,' teachers routinely invite skill or knowledge displays from students, and sometimes in such situations students indicate how and when they have come by such knowledge or a skill. Excerpt 3 shows one such case where a student's turn is taken as a claim of a learning achievement. The class is beginning to check homework together, and the teacher faces the task of selecting a student to go to the 
board to share what he or she has done. To do that, the teacher suddenly asks the class if they can do a counting rhyme in English, which itself is unrelated to the content topic of the history class (but is an example of the kinds of contingent shifts of focus to language matters at a point of need that characterise CLIL classrooms). At a point where a student response to the teacher's question is delayed, Susanna claims that the class have been doing the rhyme in pre-school (4), which is taken to imply that it is something that she has learned there. However, when the teacher subsequently puts her to demonstrate her skill, she co-constructs the rhyme with a peer before doing it independently in front of the whole class.

\section{<INSERT EXCERPT 3 ABOUT HERE>}

EXCERPT 3. Locating a Learning Achievement into a Specific Time and Place.

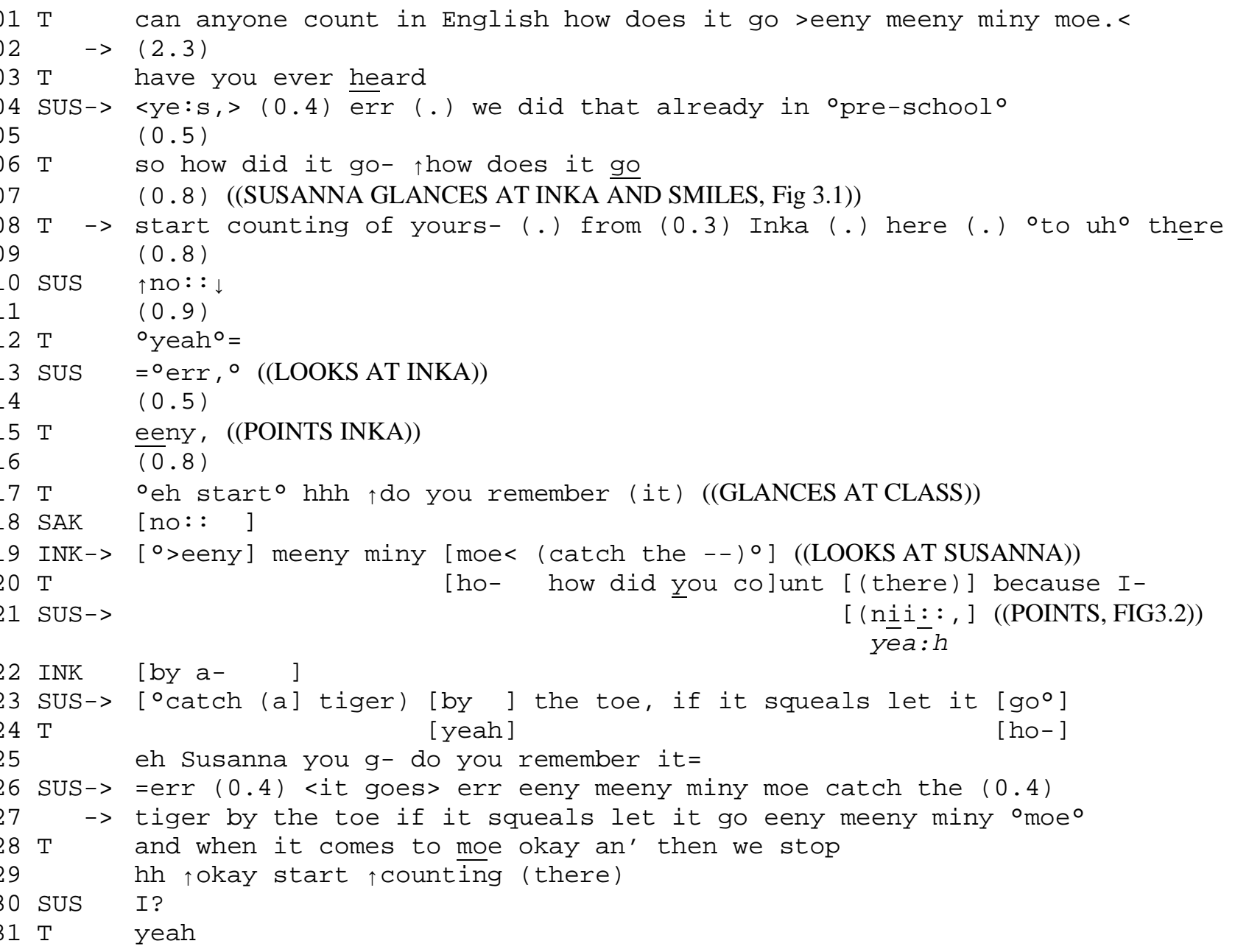




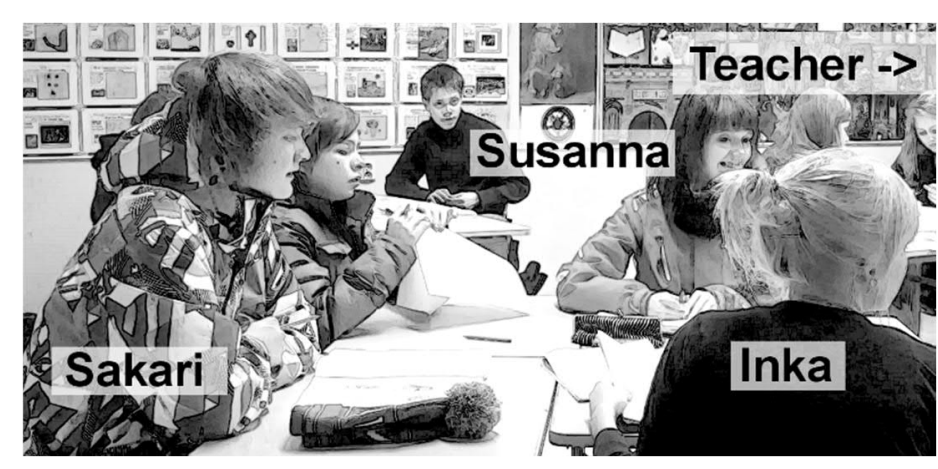

Figure 3.1. Line 7.

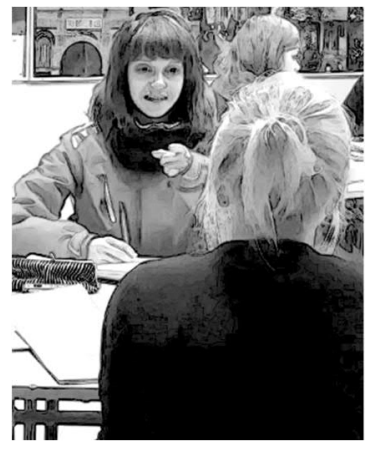

Figure 3.2. Line 21.

The teacher invites a volunteer to do a counting rhyme and provides the first few words of one such rhyme (1). She treats the subsequent silence as an indication that students may be unfamiliar with rhymes by enquiring whether students have heard about such rhymes (3). Susanna's self-selected response (4) first asserts recognition of the rhyme (yes) and then claims the ability to do it by way of stating that the students have done it already a long time ago. Such a collective claim can be heard to imply that such a rhyme is perhaps a slightly childish thing to do now that the students are teenagers, foreshadowing that its production is not a straightforward matter.

The teacher then invites Susanna to demonstrate that she can do the rhyme (6). Note how the teacher self-repairs the tense in her turn in a way that transforms the action from asking about a prior experience into a request that Susanna do the rhyme here and now to assist her in selecting a student, treating the recitation of the rhyme as a learned achievement for Susanna. However, Susanna does not begin to count, but a silence ensues during which she smiles at Inka, a student facing her (7, see also Figure 3.1). When the teacher provides a directive that specifies who should begin counting, after a 0.8second silence, Susanna refuses to do it in an intonation that can be described as 'whiny' or 'complaining' (10). Having now explicitly refused to grant the teacher's request, Susanna's lack of cooperation in the activity is apparent and becomes addressed in the ensuing interaction. ${ }^{6}$ 
Susanna turns to Inka (13) as the teacher prompts her to begin for the second time. Her softly spoken err, which is uttered with continuing intonation, projects more talk, possibly the beginning of the rhyme. It may be because of the low volume of the turn that the teacher nevertheless does not orient to it that way but instead produces a model beginning of the rhyme by uttering the first word and pointing at a student (15). As Susanna does not continue the rhyme, the teacher turns to the class in search of other knowledgeable students (17). It is in this context that Inka begins to help Susanna in peer interaction by reciting the rhyme in a soft voice (19). Susanna's emphatically produced nii ('yeah') response claims recognition of the rhyme by way of its elongated, two-peak prosody (see Sorjonen, 2001, pp. 242-247). Susanna also demonstrates that she can do the rhyme by completing Inka's beginning, still in peer interaction (23). As Susanna is once again prompted by the teacher, she produces the complete rhyme, addressing it to the teacher (26-27), before she is finally put to select a student from the class.

As Excerpt 3 showed, a retrospective reference to a (collective) learning experience can be taken as an indication that the object of that learning is transferable to, and reproducible in, the here-and-now. This can be seen in how the retrospective reference makes Susanna accountable to assist the teacher in managing the activity. However, the excerpt also suggests some ways in which such transferable and context-independent language knowledge is a complicated notion. This is visible in how it takes peer support and a 'practice round' in front of the teacher to display the learning achievement in this new context. The teacher conducts pedagogical work to assess what the delayed production of the rhyme is indicative of, which is visible as shifts in how she positions Susanna and other students in relation to whether they can do, have heard about, or remember the rhyme. However, this does not necessarily mean that Susanna would have been unable to recite the rhyme on her own from the outset. Rather, the small 'hiccups' are part of the relevant contingencies of the social situation, including the task of negotiating where to begin the rhyme as well as displaying a certain emotional stance towards nursery 
rhymes and the whole selection procedure. In this sense, even the demonstration of learning achievements is a situated interactional accomplishment.

In addition to conveying a sense of the context where learning has been achieved (such as in excerpts 2 and 3), sometimes participants provide more elaborate descriptions of past learning activities. In the present data, retrospective references to learning activities appear to cluster around episodes of checking homework in the classroom (11 out of altogether 24 cases). Homework checks are an activity that perhaps naturally engenders talk about previous 'doings.' In the data collection, these can be seen in how teachers might ask students to compare answers by discussing with each other "what was difficult" or what they "couldn't do at home," which can be seen as attempts to foster student awareness of, and retrospective talk about, problematic task aspects.

The final data excerpt shows a slightly different procedure for checking homework in a CLIL physics class in that students are writing their answers on the blackboard so that the teacher can subsequently check them and ratify correct answers. These tasks are word problems where they have had to identify the center of mass of various objects and perform calculations on forces that act upon the objects (see also Barwell, 2005, for analysis of how language and content become integrated in mathematical word problems). The students are thus required to demonstrate a learning achievement, much like Susanna in Excerpt 3, but here, their achievement to-be-shown is an ability to resolve a word problem competently by drawing sketches of the objects, identifying relevant numbers, performing calculations, and, if needed, guiding others through the calculation in L2. In Excerpt 4, a student (Neea) interrupts writing and indicates a problem to the teacher in accomplishing the task. She reconstructs her reasoning with the task at home, which is a way to check the correctness of the answer before writing it publicly and to display at least partial learning achievement to the teacher. Importantly, Neea's reconstructed task-resolving process allows the teacher to assess and correct her reasoning and thereby serves as a resource for instructional work. ${ }^{7}$ 


\section{<INSERT EXCERPT 4 ABOUT HERE>}

\section{EXCERPT 4. Describing a Previous Learning Activity (Homework)}

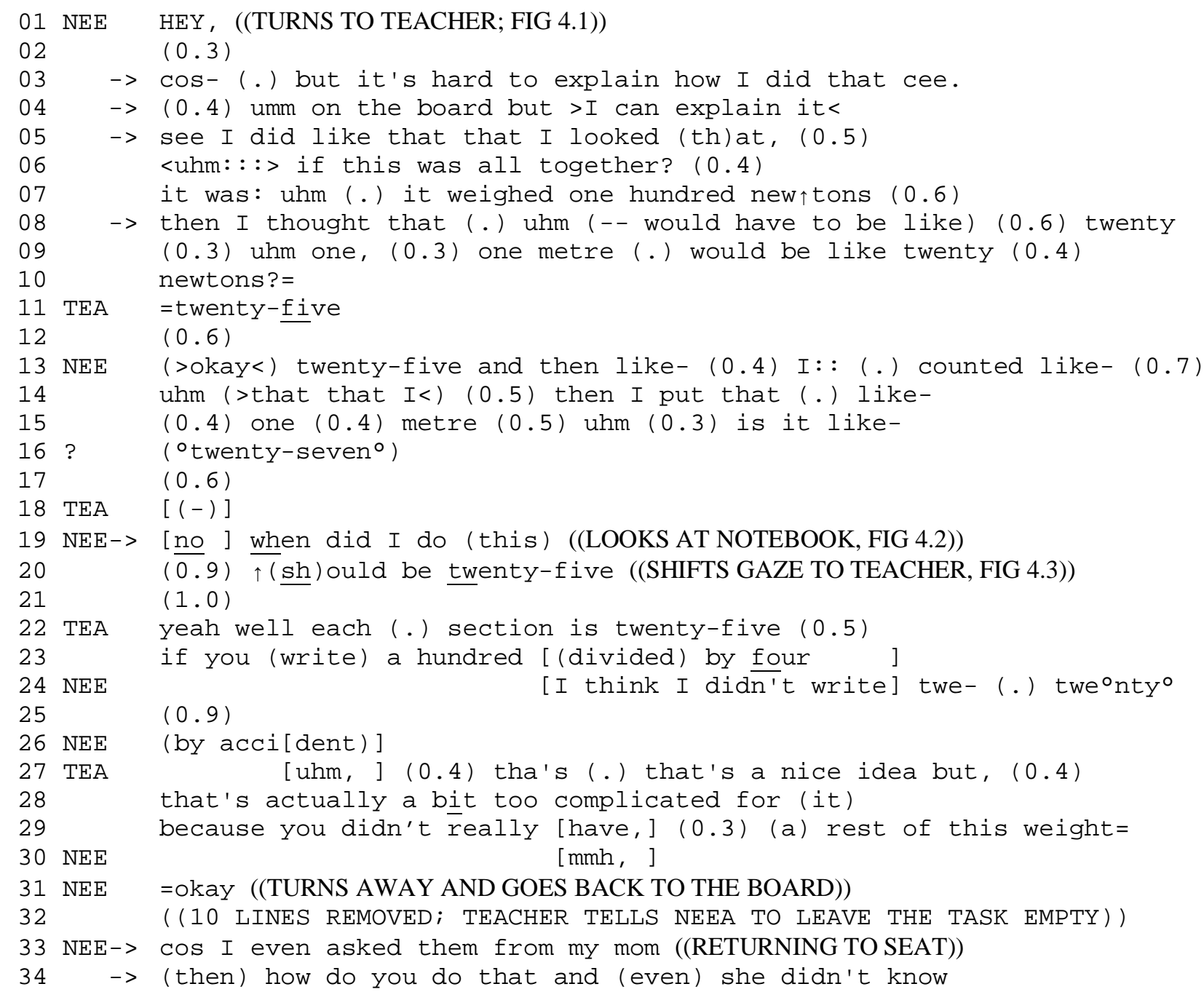

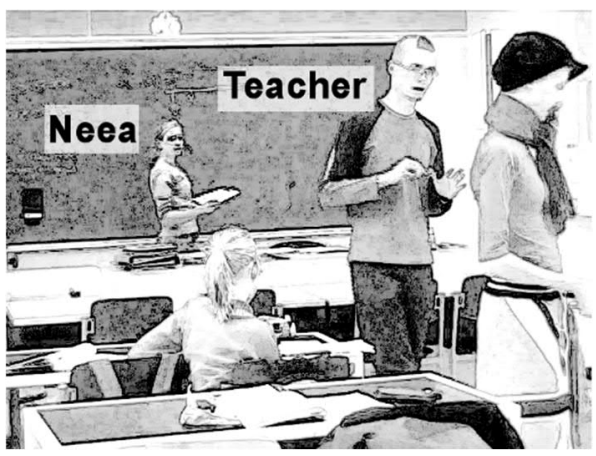

Fig 4.1. Line 1.

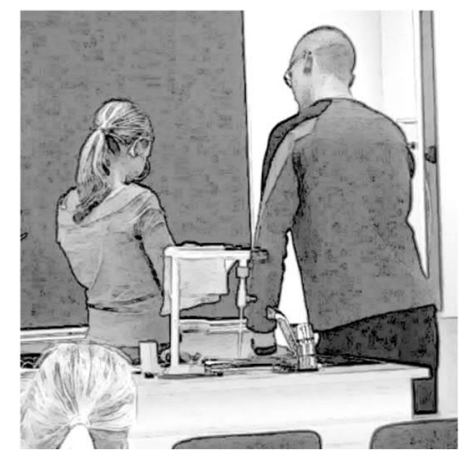

Fig 4.2. Line 19.

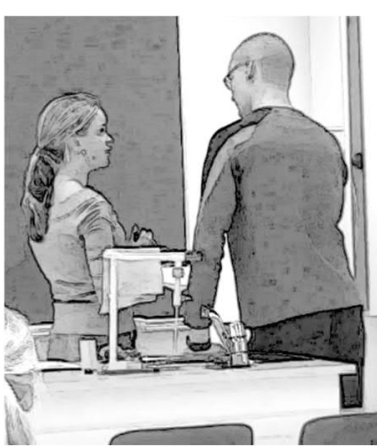

Fig 4.3. Line 20 .

Neea's call for attention (1) secures the teacher's availability and initiates one-on-one interaction with 
him. It opens an episode during which she accounts for not having written the specific answer on the board and asks for help in writing the correct answer (3-4). Notice that at this stage Neea treats herself as quite knowledgeable regarding the answer to the specific sub-task, in the sense that it can be explained. She then reconstructs in detail what she did at home (5), thereby making her learning activity available to him. This entails telling the teacher both the premise with which she approached the calculation task (if this was all together?) and making her chain of reasoning with that premise visible (7-10) by way of reporting inferences (it weighed one hundred newtons) and thoughts (then I thought...one metre would be like twenty Newtons) from the activity.

The description is heavily deictic and contextualised within the word problem task in the notebook that she shows to the teacher along with the explanation, to the degree that our sense as analysts of what aspects of the tasks exactly Neea means with Newtons and metres is unavoidably patchy (as the notebook was not collected as part of research data). However, what we can see and appreciate in a more systematic way is the public accountability of learning achievements in this situation: By explaining how she did the task, Neea claims and tries to demonstrate a partial prior learning achievement in the form of an ability to approach and complete the word problem task in a scientifically sound way, even if she cannot show it by inscription. The teacher is holding her accountable for producing such a demonstration, and Neea is making her reasoning publicly assessable so that the teacher can scrutinise it (see also Lindwall \& Lymer, 2011, p. 8). Scrutiny is evident in the teacher's immediate, latched-on correction of the calculation result (11). In this sense, Neea's account of her prior learning process is an account for being unable to provide a learning product independently at the board.

As Neea acknowledges the correction (13), she continues to report her task-resolving process, what she counted and put on paper at home. Her fragmented report (13-15) appears to go through the same relationship between metres and Newtons as prior to teacher correction, but this time it displays a 
less certain epistemic stance in that she now subjects her calculation result to the teacher's affirmation by way of a cut-off confirmation request (is it like-). It is not clear from the video whether Neea or the other student working simultaneously at the blackboard says in soft voice what appears to be number 27, also an incorrect result (16).

Neea establishes a shift from reporting her prior calculation to 'thinking' in the here-and-now (19-20). Her emphatically produced claim that the result should be twenty-five (Newtons), just as the teacher earlier pointed out (11), communicates a sudden noticing and is accompanied with a gaze shift to the teacher (see figures 4.2 and 4.3). The teacher responds by confirming the correctness of the result with a turn that explicates how one gets twenty-five (22-23). Such an explicit guidance does more than mere correction of the result (as in 11) in that it orients to the possibility that Neea's displayed indecision about the result may indicate a problematic understanding of the task, not simply a calculation error. Beginning in overlap, Neea accounts for the incorrect answer (twenty) in her notebook $(24,26)$. Parts of this turn are poorly audible, but the teacher seems to treat it as an alternative way to resolve the task, one that he nevertheless dismisses as a bit too complicated (28). He furthermore indicates how the proposed solution is problematic (29).

By this stage, it has become clear that Neea has no learning achievements to display, that she is not able to solve the task independently at the board. As Neea walks back to the board, she asks whether she should write anything, and when the teacher says she can leave the task empty (not shown in the transcript), Neea goes back to her seat. On her way, she murmurs a complaint about the task (3334). The complaint once more refers to Neea's task-resolving process at home: she accounts for the lack of a correct answer by positioning herself as someone who has gone out of her way and even asked for advice from her mother, for whom the task was too difficult. Such an extreme case formulation (Pomerantz, 1986) works to legitimize Neea's own conduct and imply that the homework was too difficult for the class. 
In summary, Excerpts 3 and 4 show a retrospective orientation to a learning achievement and activity. While knowledge of the nursery rhyme is oriented to as an achievement that Susanna has accumulated in the past, Neea treats her competence to explain and resolve the physics task in L2 as less than full from the outset (by checking her answer with the teacher). Yet, the reconstruction of her learning activity and mental processes is mobilized towards a demonstration of a partial learning achievement, which is expected from her in the situation, even if multiple instances of teacher correction convey more or less gently that no such learning has taken place.

\section{$<$ A $>$ DISCUSSION AND CONCLUSIONS}

As Ortega (2011) notes, one line that separates cognitivist and social approaches to SLA is whether language knowledge is conceptualised as abstract, "transferable across bounded minds and contexts" (p. 168), or situated in and contingent on specific contexts. The interactional episodes investigated in this article embody both kinds of conceptualisations, insofar as they show students working to manage classroom activities with the help of prior "sediments" (Eskildsen, 2018, p. 51) in their experience. Yet, in light of the present analysis, knowledge deriving from earlier experiences is not so much 'transferable' in itself as it is made to transfer by constructing change or continuity across time in some new context that has a myriad of its own contingencies. Situations involving a retrospective orientation to prior learning not only involve 'remembering' a learning achievement or activity, but using it meaningfully as a resource for social action. This article has shown how retrospection offers a resource for making sense of a new, surprising lexical meaning via previous shared and personal experiences (extract 2), for conveying that a topic of whole-class talk is a bit 'childish' (excerpt 3), and for asking help for a problematic task (extract 4). The referred-to experiences are malleable resources insofar as by connecting moments dispersed by time, participants 
can not only transform the pool of available resources in the present, but also reconfigure the past experience itself. This is the case when learners for example reconsider whether their prior knowledgeable epistemic stance actually amounted to knowledge or was merely a 'belief' (extract 2).

In instances of retrospection, participants distinguish between learning achievements (products) and activities (processes) as they manage some new activity. Many retrospective references in the data collection claim a past learning achievement. Interestingly, such references to achievements appear to be provided in situations where expectations regarding knowledge or expertise are somehow discrepant or problematic. In extract 2, the usage of the word 'pudding' on the video questions the students' understanding of the word (as settled in excerpt 1), and in extract 3, the achievement claim comes when a knowledge display by a student has been long due. Thus, by conveying a time and place of learning, a student may be heard to be doing more than merely displaying knowledge, for example, via the kinds of student responses described by Koole (2010). This may explain why they are used as a resource in situations where problems related to learning achievements surface. Moreover, while participants in pedagogical settings themselves may orient to learning achievements as being transferable and 'ownable,' the demonstration of claimed achievements is its own situated accomplishment, one that is not necessarily a straightforward matter (extracts 3 and 4 being cases in point).

In contrast to claimed achievements that typically only briefly convey to the hearer a sense of how and where something has been learnt, some retrospective references describe the learning process or activity in more detail. Perhaps surprisingly, such instances in the corpus of CLIL lessons used in this study overwhelmingly occur in episodes of homework checks in the L2 physics class (such as excerpt 4). The collection itself is small so the distribution should be taken with caution, but it may be that certain classroom activities and subject contexts engender talk about prior learning processes or activities. In checking physics homework in CLIL classrooms, students are both required to display a skill or knowledge that they are expected to have learnt so that teachers can assess their learning, and 
competence encompasses the ability to explain scientific phenomena or procedures in L2. At least in such a context, then, describing the task-resolving process by way of reporting thoughts, inferences, or social activities (such as asking for help from parents) at a very basic level displays 'trying.' As we have seen, it also allows participants to manage problems in the demonstration of full achievement in the class and can offer a way to work towards achieving learning. A possibly interesting line of further inquiry for future CA-SLA research concerns the dual nature of language learning as both a situated activity and an achievement, as well as the possible cross-fertilisation between these two 'faces' of learning in situated social interaction.

The approach adopted in this article to analyse the "lived temporality" (Deppermann \& Günthner, 2015, p. 3) of learning in single interactions as opposed to longitudinally tracking learning objects identified by the analyst raises some methodological implications for future studies. A key question in analysing the ways in which learning constitutes temporal change is whether such analysis requires longitudinal data or can be meaningfully carried out by attending to single moments in time. This article has briefly illustrated both kinds of approaches i) by tracking how participants can revisit (excerpt 2) an earlier discussion (excerpt 1) in order to recalibrate a shared learning object and ii) by analysing how participants can share more private activities or achievements which the hearers (or the analyst) have not witnessed (excerpts 3-4). Intuitively, it would seem that some access to that which participants are referring to is necessary in order to know what moments or experiences participants refer to, ideally in the form of a video recording of the prior situation(s). On the other hand, at least a partial sense of the prior learning that a retrospective reference targets is provided to the analyst because participants need to make such references accountable and intelligible to their hearers-who face the task of interpreting what social action the reference is a meaningful part of. However, the problem is that such references are often recipient-designed to a community that does not by definition encompass the researcher (such as classroom peers). This means that gaining a sense of what 
retrospective references are used for in interaction can be a matter of having sufficient ethnographic knowledge of the setting and the participants. ${ }^{8}$ Incidentally, such analytical difficulties in recognising retrospection in the first place may explain the relatively small size of the present data collection. In any case, even if the analysis of single moments of retrospection does not enable the researcher to verify whether or not a learner actually learned something in 'pre-school' when she claims to have done so (excerpt 3), analytically this is perhaps not the most interesting question to ask. Instead, much can be said about the situated relevance of observably mobilised prior learning experiences and how participants produce their current understandings, states of knowledge, or abilities as similar/dissimilar with one held in the past as a sequential accomplishment. These are questions to which a CA methodology is well-suited to provide answers.

To conclude, an inquiry into the ways in which language learning constitutes praxeological construction of change over time in situated learning activities is largely missing in the current CASLA literature. As Lilja and Piirainen-Marsh (2018) note, retrospection shows what "participants themselves treat as worth telling and learning" (p. 26). Therefore, directing analytical attention on observable uses of the past in interaction could provide an analytical entry point for exploring how learning involves the bringing together of sometimes unexpected non-local resources-experiences, achievements, cognitive states, and so on-dispersed by time and place. Above all, this article has attempted to show that language learning is an umbrella term for transformations of knowledge, understanding, and skills, and that much can be discovered by attending to how learners report, produce, and manage such transformations in public view.

\section{ACKNOWLEDGMENTS}

I would like to express my gratitude to former editor Heidi Byrnes for her guidance and encouragement in the early days of the submission process and to current editor Marta Antón for her help in its final 
stages. I also thank the anonymous reviewers and Leila Kääntä for their insightful and constructive suggestions for improving different versions of the article. Any remaining errors, omissions, and shortcomings are my own. The study has been funded by the Academy of Finland (Grant no. 310387).

\section{NOTES}

1 Typically, longitudinal studies of L2 IC use the word 'development,' not 'learning,' to refer to the observed change over time. While the relationship between these two terms is not always explicated, Hall \& Pekarek Doehler (2011) convey a sense that they are seen as different as they relate development to "...not learning processes, but the products of learning, that is more advanced competencies at a given moment in time" (p. 7). The objects of development are perhaps broader and more complex than what is traditionally associated with 'language learning' but instead involves what Pekarek Doehler \& Berger (2016) view as “"methods” for action” (p. 2).

2 In CA-SLA research there seems to have been more work directly addressing 'learning' than in EMCA literature involving other kinds of pedagogical contexts, in which the focus has more often been on the notions of 'instruction' and 'instructed action’ (e.g., Lindwall, Lymer, \& Greiffenhagen, 2015; Zemel \& Koschmann, 2014).

3 And as Kasper and Wagner (2018, p. 86) note, this is where learning interactions in CLIL classes and "institutional interaction in the wild" overlap.

4 The fourth student (Tuuli) follows the teacher throughout the extract and does not participate in the talk.

5 Interestingly, the students do not problematize at any point how the determinant 'Yorkshire' may configure the meaning of the word 'pudding;' for the analyst, it is tempting to see that that exactly is what in the end prevents them from resolving the conceptual conflict. 
6 While Susanna provides no account for her refusal (beyond the implied childishness), the activity itself is interactionally and socially delicate in two ways. Not only does Susanna need to 'deliver' what she has claimed to be able to do, but, by eventually selecting a student with the rhyme, she will be putting someone in the situation of having to show his or her homework to the class. Indeed, the teacher has oriented to the selection procedure as a problematic affair already from the outset in that she has initiated the whole collaborative production of the rhyme as opposed to merely naming a student to go to the board.

7 As Neea turns towards the teacher and asks him to check her answer to task item ' $C$ ' at line 1 , she has sketched an inscription of the object (a balancing plank) on the board. The task turned out to be difficult for all students, and before beginning to write, Neea had told the teacher that she was 'not sure' of the answer to some sub-tasks but willing to 'try'. In the subsequent situation where the teacher reviewed Neea's answer (along with other homework answers), the teacher corrected Neea's sketch of the plank, not only her answer to item ' $\mathrm{C}$ '.

8 A case in point is Pekarek Doehler's (2010, pp. 111-114) description of how the researcher and a learner invoke a prior shared moment merely by glancing each other in passing.

\section{REFERENCES}

Andrée, M., Wickman, P.-O., \& Lager-Nyqvist, L. (2017). Remembering as Instructional Work in the Science Classroom. In Å. Mäkitalo, P. Linell, \& R. Säljö (Eds.), Memory Practices and Learning: Interactional, Institutional and Sociocultural Perspectives (pp. 75-92). Charlotte, NC: IAP.

Barwell, R. (2005). Integrating language and content: Issues from the mathematics classroom. Linguistics and Education, 16, 205-218.

Bolden, G. B. (2011). On the Organization of Repair in Multiperson Conversation: The Case of 
“Other”-Selection in Other-Initiated Repair Sequences. Research on Language and Social Interaction, 44, 237-262.

Burch, A. R. (2014). Pursuing information: A conversation analytic perspective on communication strategies. Language Learning, 64, 651-684.

Cekaite, A. (2007). A child's development of interactional competence in a Swedish L2 classroom. Modern Language Journal, 91, 45-62.

Dalton-Puffer, C., \& Smit, U. (2013). Content and Language Integrated Learning: A Research Agenda. Language Teaching, 46, 545-559.

Deppermann, A., \& Günthner, S. (2015). Temporality in interaction. In A. Deppermann \& S. Günthner (Eds.), Temporality in interaction (pp. 1-23). Philadelphia/Amsterdam: John Benjamins.

Ellis, R. (2010). Theoretical pluralism in SLA: A way forward? In P. Seedhouse, S. Walsh, \& C. Jenks (Eds.), Conceptualising 'learning’ in Applied Linguistics (pp. 23-51). New York: Palgrave Macmillan.

Eskildsen, S. W. (2018). 'We're Learning a Lot of New Words': Encountering New L2 Vocabulary Outside of Class. Modern Language Journal, 102(Supplement 2018), 46-63.

Eskildsen, S. W., \& Majlesi, A. R. (2018). Learnables and Teachables in Second Language Talk: Advancing a Social Reconceptualization of Central SLA Tenets. Introduction to the Special Issue. Modern Language Journal, 102(Supplement 2018), 3-10.

Eskildsen, S. W., \& Theodórsdóttir, G. (2017). Constructing L2 learning spaces: Ways to achieve learning inside and outside the classroom. Applied Linguistics, 38, 143-164.

Eskildsen, S. W., \& Wagner, J. (2015). Embodied L2 construction learning. Language Learning, 65, $268-297$.

Gardner, R. 2008. Conversation analysis and orientation to learning. Journal of Applied Linguistics, 5, 229-244. 
Garfinkel, H. (1967). Studies in ethnomethodology. Englewood Cliffs,NJ.: Prentice-Hall.

Hall, J.K., \& Pekarak-Doehler, S. (2011). L2 interactional competence and development. In J.K. Hall, J. Hellermann, \& S. Pekarak Doehler (Eds.), Interactional competence and development (pp. 115). Clevedon: Multilingual Matters.

Hauser, E. (2011). On the Danger of Exogenous Theory in CA-for-SLA: A Response to Hellermann and Cole (2009). Applied Linguistics, 32, 348-352.

Hauser, E. (2013). Stability and change in one adult's second language English negation. Language Learning, 63, 463-498.

Hauser, E. (2017). Learning and the immediate use (fulness) of a new vocabulary item. Modern Language Journal, 101, 712-728.

Hellermann, J. (2009). Looking for Evidence of Language Learning in Practices for Repair: A Case Study of Self-Initiated Self-Repair by an Adult Learner of English. Scandinavian Journal of Educational Research, 53, 113-132.

Hellermann, J. (2011). Members' methods, members competencies: Looking for evidence of language learning in longitudinal investigation of other-initiated repair. In J. K. Hall, J. Hellermann, \& S. Pekarek Doehler (Eds.), L2 interactional competence and development (pp. 147-171). Bristol, UK: Multilingual Matters.

Hellermann, J., \& Cole, E. (2009). Practices for social interaction in the language-learning classroom: Disengagements from dyadic task interaction. Applied Linguistics, 30, 186-215.

Heritage, J. (2012). Epistemics in Action: Action Formation and Territories of Knowledge. Research on Language and Social Interaction, 45, 1-29.

Heritage, J., \& Raymond, G. (2005). The terms of agreement: Indexing epistemic authority and subordination in talk-in-interaction. Social Psychology Quarterly, 68, 15-38.

Jakonen, T. (2014). Building bridges: How secondary school pupils bring their informal learning 
experiences into a Content and Language Integrated (CLIL) classroom. Apples: Journal of Applied Language Studies, 8, 7-28.

Kääntä, L. (2014). From noticing to initiating correction: Students' epistemic displays in instructional interaction. Journal of Pragmatics, 66, 86-105.

Kasper, G. (2009). Locating cognition in second language interaction and learning: Inside the skull or in public view? IRAL-International Review of Applied Linguistics in Language Teaching, 47, 1136.

Kasper, G., \& Wagner, J. (2018). Epistemological Reorientations and L2 Interactional Settings: A Postscript to the Special Issue. Modern Language Journal, 102(Supplement 2018), 82-90.

Koole, T. (2010). Displays of epistemic access: Student responses to teacher explanations. Research on Language and Social Interaction, 43, 183-209.

Koschmann, T. (2013). Conversation analysis and learning in interaction. In C. A. Chapelle (Ed.), The encyclopedia of applied linguistics (pp. 1038-1043). Wiley Online Library.

Larsen-Freeman, D. (2007). Reflecting on the cognitive-social debate in second language acquisition. Modern Language Journal, 91, 773-787.

Lee, J., \& Burch, A. R. (2017). Collaborative planning in process: An ethnomethodological perspective. TESOL Quarterly, 51, 536-575.

Lee, Y.-A. (2010). Learning in the contingency of talk-in-interaction. Text \& Talk, 30, 403-422.

Lee, Y.-A., \& Hellermann, J. (2014). Tracing developmental changes through Conversation Analysis: cross-sectional and longitudinal analysis. TESOL Quarterly, 48, 763-788.

Lilja, N. (2014). Partial repetitions as other-initiations of repair in second language talk: Reestablishing understanding and doing learning. Journal of Pragmatics, 71, 98-116.

Lilja, N., \& Piirainen-Marsh, A. (2018). Connecting the Language Classroom and the Wild: Reenactments of Language Use Experiences. Applied Linguistics (advance access), 1-31. 
Lindwall, O., \& Lymer, G. (2011). Uses of 'understand' in science education. Journal of Pragmatics, $43,452-474$.

Lindwall, O., Lymer, G. \& Greiffenhagen, C. 2015. The sequential analysis of instruction. In N. Markee (Ed.), The handbook of classroom discourse and interaction (pp. 142-157). Malden, MA: Wiley-Blackwell.

Macbeth, D. (2014). Studies of work, instructed action, and the promise of granularity: A commentary. Discourse Studies, 16, 295-308.

Majlesi, A. R., \& Broth, M. (2012). Emergent learnables in second language classroom interaction. Learning, Culture and Social Interaction, 1, 193-207.

Markee, N. (2008). Toward a learning behavior tracking methodology for CA-for-SLA. Applied Linguistics, 29, 404-427.

Markee, N., \& Kunitz, S. (2013). Doing planning and task performance in second language acquisition: An ethnomethodological respecification. Language Learning, 63, 629-664.

Melander, H., \& Aarsand, P. (2017). Practices of remembering: Organizing math activities in a first grade classroom. In Å. Mäkitalo, P. Linell, \& R. Säljö (Eds.), Memory Practices and Learning: Interactional, Institutional and Sociocultural Perspectives (pp. 175-200). Charlotte, NC: IAP.

Merke, S. (2016). Establishing the explainable in Finnish-as-a-foreign-language classroom interaction: Student-initiated explanation sequences. Learning, Culture and Social Interaction, 9, 1-15.

Nguyen, H. T. (2011). Achieving recipient design longitudinally: Evidence from a pharmacy intern in patient consultations. In J. K. Hall, J. Hellermann, \& S. Pekarek Doehler (Eds.), L2 interactional competence and development (pp. 173-205). Bristol, UK: Multilingual Matters.

Nikula, T., Dalton-Puffer, C., Llinares, A., \& Lorenzo, F. (2016). More than content and language: The complexity of integration in CLIL and bilingual education. In T. Nikula, E. Dafouz, P. Moore, \& U. Smit (Eds.), Conceptualising integration in CLIL and multilingual education (pp. 1-28). 
Bristol: Multilingual Matters.

Nikula, T., \& Mård-Miettinen, K. (2014). Language learning in immersion and CLIL classrooms. Handbook of Pragmatics, 18, 1-24.

Ortega, L. (2011). SLA after the social turn: Where cognitivism and its alternatives stand. In D. Atkinson (Ed.), Alternative Approaches to Second Language Acquisition (pp. 167-180). New York: Routledge.

Ortega, L., \& Iberri-Shea, G. (2005). Longitudinal research in second language acquisition: Recent trends and future directions. Annual Review of Applied Linguistics, 25, 26-45.

Pekarek Doehler, S. (2010). Conceptual changes and methodological challenges: On language and learning from a conversation analytic perspective on SLA. In P. Seedhouse, S. Walsh, \& C. Jenks (Eds.), Conceptualising 'learning’ in applied linguistics (pp. 105-126). New York: Palgrave Macmillan.

Pekarek Doehler, S., \& Berger, E. (2016). L2 interactional competence as increased ability for contextsensitive conduct: A longitudinal study of story-openings. Applied Linguistics (advance access, available at https://doi.org/10.1093/applin/amw021).

Pekarek Doehler, S. \& Lauzon, V. F. 2015. Documenting change across time: Longitudinal and crosssectional CA studies of classroom interaction. In N. Markee (Ed.), The handbook of classroom discourse and interaction (pp. 409-424). Malden, MA: Wiley-Blackwell.

Pomerantz, A. (1986). Extreme case formulations: A new way of legitimating claims. Human Studies, 9, 219-230.

Sacks, H., Schegloff, E., \& Jefferson, G. (1974). A simplest systematics for the organization of turntaking for conversation. Language, 50, 696-735.

Sahlström, F. (2011). Learning as social action. In J. K. Hall, J. Hellermann. \& S. Pekarek Doehler (Eds.), L2 interactional competence and development (pp. 45-65). Bristol, UK: Multilingual 


\section{Matters.}

Seedhouse, P. (2010). A framework for conceptualising learning in applied linguistics. In P.

Seedhouse, S. Walsh, \& C. Jenks (Eds.), Conceptualising 'learning' in applied linguistics (pp. 240-256). New York: Palgrave Macmillan.

Sorjonen, M.-L. (2001). Responding in conversation: A study of response particles in Finnish.

Philadelphia/Amsterdam: John Benjamins.

Theodórsdóttir, G. (2018). L2 teaching in the wild: A closer look at correction and explanation

practices in everyday L2 interaction. Modern Language Journal, 102(Supplement 2018), 30-45.

van Compernolle, R. A. (2010). Incidental microgenetic development in second-language teacher-

learner talk-in-interaction. Classroom Discourse, 1, 66-81.

Weatherall, A. (2011). I don’t know as a prepositioned epistemic hedge. Research on Language and Social Interaction, 44, 317-337.

Zemel, A., \& Koschmann, T. (2014). "Put your fingers right in here": Learnability and instructed experience. Discourse Studies, 16, 163-183.

\section{APPENDIX. TRANSCRIPTION SYMBOLS.}

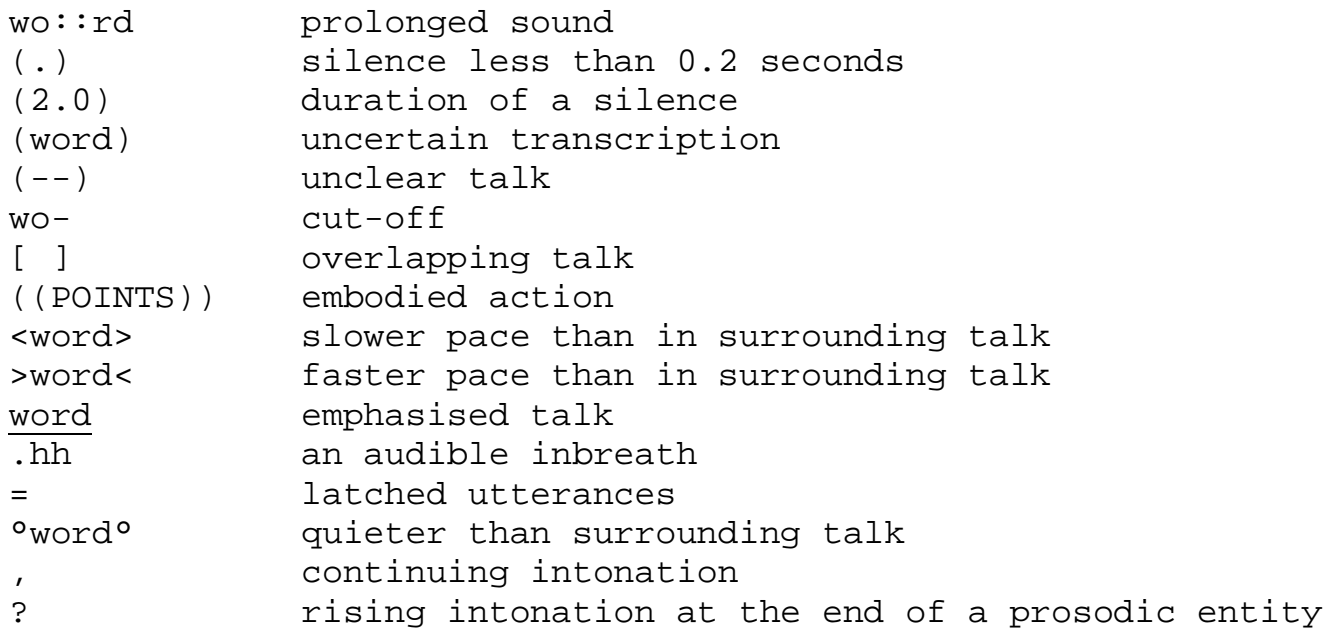


$\uparrow \quad \downarrow$

italics change in pitch height

English translation of a Finnish turn constructional unit 